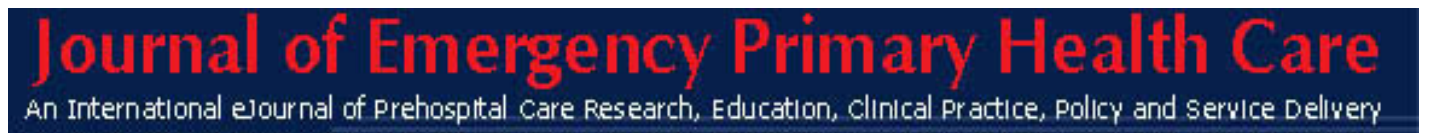

ISSN 1447-4999

\title{
EDUCATION
}

\section{Subconscious passive learning of CPR techniques through television medical drama}

Article No. 990117

\author{
A. Eisenman $M^{a b c}$ V. Rusetski $M^{a}$ Z. Zohar RN MA ${ }^{a b}$ D. Avital RN MA \\ J. Stolero $\mathrm{MD}^{\mathrm{a}}$ \\ ${ }^{\boldsymbol{a}}$ The Department of Emergency Medicine, ${ }^{\boldsymbol{b}}$ The resuscitation committee, The Western Galilee \\ Hospital, Naharia, ${ }^{c}$ The Rappaport Faculty of Medicine, Technion, Haifa, Israel
}

\begin{abstract}
A cardiac arrest victim's chances of survival are largely dependant on the availability at the scene, of a witness familiar with CPR skills. Many efforts have been invested in teaching CPR skills to as many people as possible and new ways are constantly being researched to distribute and extend these skills to the wider population. We report a case whose survival was due to CPR performed by a lay family member with no previous official training in resuscitation. The rescuer admitted that she had recalled the CPR technique from a popular medical drama on television (TV) and that she was absolutely unaware of her CPR potential capabilities. TV producers and health policy makers should exploit highly rated TV feature programs such as medical dramas to transmit useful hidden messages such as CPR skill to the public. In due time this policy may prove to be a life saver.
\end{abstract}

Keywords: cardiopulmonary resuscitation; chain of survival; CPR; distance education; informal education; layperson CPR; passive learning; skill achievements; sudden cardiac arrest.

\section{INTRODUCTION}

Unfortunately, as indicated by the American Heart Association's Guideline 2000, only about $5 \%$ of out-of-hospital sudden cardiac arrest victims survive. As a rule they all belong to a group of patients whose collapse is witnessed by a bystander and who receive cardiopulmonary resuscitation (CPR) within 4 to 5 minutes, and defibrillation within 8 to 10 minutes. ${ }^{1}$

Laypersons witnessing a cardiac arrest are often unaware of their own hidden capability to save another's life. We have recently experienced a case in which survival was crucially due to the fortunate intervention of a layperson with no formal training in CPR, but who appeared to acquire some notions through watching CPR being performed on a TV medical drama. This case highlights how passive, often subconscious learning of CPR skills through television dramas can actually contribute to saving lives, and how society can benefit from highly rated television entertainment programs distributing useful messages such as CPR skills to a captive audience. 


\section{CASE HISTORY}

A 71 years old male was watching television while his wife of the same age left to do some shopping. Upon returning home she found her husband lying unconscious on the floor, gasping for breath. The horrified woman suspected that she was, in fact, witnessing a cardiac arrest and recognized that unless CPR was performed at once she was about to lose her husband. She had no medical education and had never attended a CPR class. She recalled however, watching similar cases on her favorite television medical drama on several occasions and tried to recall what had occurred to save the victims. She performed heart compressions and mouth-to-mouth ventilation to the best of her recollection. After a few minutes she noticed that her husband's facial expression had somewhat changed. She then halted her efforts for a minute to call for help and to regain her strength. She summoned the paramedics and resumed CPR. The paramedics found the patient to be in ventricular fibrillation on their arrival 15 minutes after collapse. They continued CPR and after two defibrillation attempts, the patient regained a viable sinus rhythm and restoration of pulse and blood pressure. The patient was intubated and promptly transferred to our hospital where he regained consciousness on the same day. A subsequent electrocardiogram revealed an extensive myocardial infarction. The patient made a full recovery and was discharged from hospital a week later with no neurological deficit. The case received significant media attention with the rescuer indicating that she never thought she was capable of saving a life. Ironically, her husband told the press that he had always teased her about watching these "foolish programs".

\section{DISCUSSION}

Immediate access to help and CPR, i.e. chest compressions and ventilation, are the first links of the Chain of Survival defined by the American Heart Association (early access, early CPR, early defibrillation and early ALS). ${ }^{2}$ Although early defibrillation is considered the crucial factor for restoring spontaneous circulation in cardiac arrest patients with ventricular fibrillation, CPR may buy precious time until a defibrillator is available. ${ }^{2}$ Recent studies have also shown that after prolonged ventricular fibrillation, the rates of return of spontaneous circulation (ROSC) and survival may be further improved if defibrillation is delayed so that CPR can be given first. ${ }^{3}$ Furthermore, survivors who received CPR prior to arrival of the ambulance showed a trend towards overall better post arrest cognitive functioning and significant better immediate memory. ${ }^{4}$

The distribution of CPR skills to as many people as possible in order to promote the Chain of Survival became a declared aim of organizations such as the American Heart Association and the European Resuscitation Council. ${ }^{5}$ Tremendous effort has been invested throughout the last four decades, on training medical staff and the lay public in CPR. ${ }^{5,6,7}$ Most of these efforts have focused on active training through formal courses and the potential significance and implications of passive skill achievements through hidden messages by the mass media, have been largely ignored.

Television has a powerful impact on the public. The influence of television is wider than education. ${ }^{\mathbf{8}}$ It has a vital role in both leading and reflecting changing public attitudes. ${ }^{\mathbf{8}}$ Currently, an average American child or adolescent spends more than 21 hours per week viewing television ${ }^{\mathbf{9}}$ passively absorbing an enormous amount of information. ${ }^{\mathbf{1 0}}$ Indeed, 
authorities are troubled by the negative educational impact of crime series, commercials and pornography on television viewers.

There is however a positive side, as modern mass media offers new applications of passive learning in various subjects such as CPR which can reach those not captured through traditional programs. CPR may seem dramatic to the layperson, and TV medical programs tend to use CPR to move the story along. ${ }^{11}$ In one study, at least half of the students attending formal CPR classes noted that TV popular medical dramas had motivated them to take the course, recounting events of a particularly spectacular CPR-based "save" on television. ${ }^{\mathbf{1 2 , 1 3}}$ Another study confirmed that $92 \%$ of people who were older than 62 years of age received most of their information about CPR from television ${ }^{\mathbf{1 4}}$ as occurred in this case.

Although promising, there are a number of limitations to passive learning via television which need to be considered. Firstly, it is unclear how much of the information acquired passively through television is actually retained in memory. Some suggest that personal motivation may be an essential contributing factor. It was shown, in fact, that people concerned about the health of a close family member, better recall CPR skills demonstrated on TV than people who are not emotionally involved. ${ }^{15,16}$ In this case, however, cardiac arrest had not been anticipated and the recall of CPR skills from TV can therefore not be attributed to familial motivation.

Secondly, the information provided by a television series can be inaccurate. ${ }^{\mathbf{1 4}}$ This is highlighted in an American study which reported that of the 60 instances of CPR performed on "ER", "Chicago Hope" and "Rescue 911" during the 1994-1995 television season, 77 percent of the patients survived immediately after cardiac arrest and 67 percent appeared to survive long-term. This, unfortunately, is in contrast to the relatively poor survival rates, reported in medical literature, which range from 2 to 30 percent for out-of-hospital cardiac arrests and about 7 to 15 percent for in-hospital cardiac arrests. ${ }^{17}$ Interestingly it seems that the overall survival rate of patients having undergone CPR in British television medical dramas, tend to be more realistic than in American medical dramas. ${ }^{\mathbf{1 8}}$

Thirdly, it is known that the ability of a layperson to provide adequate compression and airway control depends on the quality and frequency of practical training, and that CPR skill is often inadequate even after formal education. Having said that, very little can be commented on, regarding the quality of CPR performance when the technique has been learned from watching a television program. Some authors warn that the implicit risks of adopting "bad" CPR skills from a television drama may be as harmful as the false impression of its success. ${ }^{13,19}$ Given the poor prognosis associated with out-of-hospital cardiac arrest however, it is clearly better to do something than do nothing at all. In other words, when death is the likely scenario, whatever CPR skill is exercised and no matter how it is implemented, only serves to increase the chances of saving a life.

This case report constitutes probably just a drop in a vast ocean of many more, unreported, cardiac arrest victims whose lives have been saved by an unexpected "TV graduate" rescuer. Since many of these rescuers are often unaware of their own CPR skill, the actual pool of such potential CPR providers is underestimated and cannot be accurately evaluated.

Embedding deliberate transmissions of important useful messages such as CPR through highly rated popular television dramas should be encouraged as it offers the potential to improve CPR awareness in the community and in the process, improve survival from cardiac arrest. 
Drama producers should be applauded for motivating people to learn a valuable skill through television as it adds value to these programs. ${ }^{12,13}$ TV medical dramas should be perceived not only as mere entertainment but also as a potentially powerful educational tool that may save lives. Given the declared aim to transform as many people as possible into potential early CPR providers, health policy makers and TV producers should collaborate in utilizing television to spread deliberate useful information such as CPR not only through official broadcasted education programs, but also unofficially - through highly rated medical dramas or other popular entertainment programs. In doing so however, it is important that they also take responsibility for ensuring that skills are simulated correctly and that viewers have a clear understanding of the implications of their actions.

\section{REFERENCES}

1. Weaver WD, Cobb LA, Hallstrom AP, Copass MK, Ray R, Emery M, Fahrenbruch C. Considerations for improving survival from out-of-hospital cardiac arrest Ann Emerg Med. 1986;15:1181-6.

2. Cummings RO, Ornate JP, This WH, Pepe PE. Improving survival from sudden cardiac arrest: the 'chain of survival' concept: a statement for health professionals from the Advanced Cardiac Life Support Subcommittee and the Emergency Cardiac Care Committee, American Heart Association. Circulation 1991;83:1832-47.

3. Eftestøl T, Wik L, Sunde K, Steen PA. Effects of Cardiopulmonary Resuscitation on Predictors of Ventricular Fibrillation Defibrillation Success During Out-of-Hospital Cardiac Arrest. Circulation. 2004;110(1):10-15.

4. Van Alem AP, de Vos R, Schmand B, Koster RW. Cognitive impairment in survivors of out-of-hospital cardiac arrest. Am Heart J. 2004;148(3):416-21.

5. Cardiopulmonary resuscitation: statement by the Ad Hoc Committee on Cardiopulmonary Resuscitation of the Division of Medical Sciences, National Research Council, JAMA, 1966;198:372-79.

6. Cardiopulmonary Resuscitation. Conference Proceedings, May 23, 1966. Washington, DC: National Academy of Sciences, National Research Council; 1967.

7. Standards for cardiopulmonary resuscitation (CPR) and emergency cardiac care (ECC). JAMA. 1974;227:833-68.

8. Blunkett D. Education Secretary, in BBC News at 20:11 GMT Thursday, April 15, 1999.

9. 1998 Report on Television. New York, NY: Nielsen Media Research; 1998.

10. Policy Statement, Media Education (RE9911), Committee on Public Education, American Academy of Pediatrics, Pediatrics. 1999;104:341-43.

11. Kruszelnicki, KS. TV doctors; Australian Broadcasting Corporation, 1997.

12. Troy A. Cardiopulmonary resuscitation on television - letter to the editor, N Engl J Med 1996;335(21):1605-07.

13. Markert RJ, Saklayen MG., Mulcahy HE, Ellison MM, Farthing MJG, Wallack EM et al. Cardiopulmonary Resuscitation on Television. N Engl J Med. 1996;335(21):160507.

14. Andrew Holtz, Experts: Medical dramas skew the reality of CPR. in CNN June 13,1996. [ONLINE]Available: http://edition.cnn.com/HEALTH/9606/13/cpr.tv/index.html

15. Dracup K, Doering LV, Moser DK, Evangelista L. Retention and use of cardiopulmonary resuscitation skills in parents of infants at risk for cardiopulmonary arrest. Pediatr. Nurs. 1998;24:219-25. 
16. Moser DK, Dracup K, Guzy PM, Taylor SE, Breu C. Cardiopulmonary resuscitation skills retention in family members of cardiac patients. Am J Emerg Med. 1990;8:498503.

17. Diem SJ, Lantos JD, Tulsky JA. Cardiopulmonary resuscitation on television miracles and misinformation. N Engl J Med 1996(24);334:1578-82.

18. Gordon PN, Williamson S, Lawler PG. As seen on TV: Observational study of cardiopulmonary resuscitation in British television medical dramas. BMJ 1998;317:780-83.

19. Chheda M, Hauptman PJ. Cardiopulmonary resuscitation on television - letter to the editor, N Engl J Med 1996;335:1606-07.

This article was peer reviewed for the Journal of Emergency Primary Health Care Vol. 1 (3-4), 2003

\section{Author Disclosure:}

The authors have no financial, personal or honorary affiliations with any commercial organization directly involved or discussed in this study. 